\title{
THE
}

2016

\section{Denitrifying Bioreactors for Nitrate Removal: A Meta-Analysis}

Kelly Addy

University of Rhode Island

Arthur J. Gold

University of Rhode Island, agold@uri.edu

Laura E. Christianson

Mark B. David

Louis A. Schipper

See next page for additional authors

Follow this and additional works at: https://digitalcommons.uri.edu/nrs_facpubs

Creative Commons License

(c) (1) (8)

This work is licensed under a Creative Commons Attribution-Noncommercial-No Derivative Works 4.0 License.

\section{Citation/Publisher Attribution}

Addy, K., A. J. Gold, L. E. Christianson, M. B. David, L. A. Schipper, and N. A. Ratigan. 2016. Denitrifying

Bioreactors for Nitrate Removal: A Meta-Analysis. J. Environ. Qual. 45:873-881. doi: 10.2134/

jeq2015.07.0399

Available at: http://dx.doi.org/10.2134/jeq2015.07.0399

This Article is brought to you for free and open access by the Natural Resources Science at DigitalCommons@URI. It has been accepted for inclusion in Natural Resources Science Faculty Publications by an authorized administrator of DigitalCommons@URI. For more information, please contact digitalcommons-group@uri.edu. 


\section{Authors}

Kelly Addy, Arthur J. Gold, Laura E. Christianson, Mark B. David, Louis A. Schipper, and Nicole A. Ratigan 


\title{
Denitrifying Bioreactors for Nitrate Removal: A Meta-Analysis
}

\author{
Kelly Addy, Arthur J. Gold, ${ }^{*}$ Laura E. Christianson, Mark B. David, Louis A. Schipper, and Nicole A. Ratigan
}

\begin{abstract}
Meta-analysis approaches were used in this first quantitative synthesis of denitrifying woodchip bioreactors. Nitrate removal across environmental and design conditions was assessed from 26 published studies, representing 57 separate bioreactor units (i.e., walls, beds, and laboratory columns). Effect size calculations weighted the data based on variance and number of measurements for each bioreactor unit. Nitrate removal rates in bed and column studies were not significantly different, but both were significantly higher than wall studies. In denitrifying beds, wood source did not significantly affect nitrate removal rates. Nitrate removal (mass per volume) was significantly lower in beds with <6-h hydraulic retention times, which argues for ensuring that bed designs incorporate sufficient time for nitrate removal. Rates significantly declined after the first year of bed operation but then stabilized. Nitrogen limitation significantly affected bed nitrate removal. Categorical and linear assessments found significant nitrate removal effects with bed temperature; a $Q_{10}$ of 2.15 was quite similar to other studies. Lessons from this meta-analysis can be incorporated into bed designs, especially extending hydraulic retention times to increase nitrate removal under low temperature and high flow conditions. Additional column studies are warranted for comparative assessments, as are field-based studies for assessing in situ conditions, especially in aging beds, with careful collection and reporting of design and environmental data. Future assessment of these systems might take a holistic view, reviewing nitrate removal in conjunction with other processes, including greenhouse gas and other unfavorable by-product production.
\end{abstract}

\section{Core Ideas}

- Denitrifying beds may reduce water quality degradation and treat onsite wastewaters.

- Extending HRT can help manage nitrate under low temperatures and high flows.

- Multiyear laboratory column and in-field bed assessments are needed to refine designs.

Copyright $\odot$ American Society of Agronomy, Crop Science Society of America, and Soil Science Society of America. 5585 Guilford Rd., Madison, WI 53711 USA.

All rights reserved.

\section{J. Environ. Qual. 45:873-881 (2016)}

doi:10.2134/jeq2015.07.0399

This is an open access article distributed under the terms of the CC BY-NC-ND

license (http://creativecommons.org/licenses/by-nc-nd/4.0/)

Supplemental material is available online for this article.

Received 30 July 2015.

Accepted 9 Dec. 2015.

*Corresponding author (agold@uri.edu).
$\mathrm{E}$ XCESS NITRATE-NITROgen losses from agricultural watersheds generate a host of water quality problems around the globe, including eutrophication, algae blooms, and fish kills (Howarth et al., 2000; Diaz, 2001; Nixon et al., 2001; Howarth, 2008; Billen et al., 2013; Erisman et al., 2013). Among the many approaches considered to address this problem, the development and use of passive denitrifying bioreactors has drawn increasing interest in the past two decades. These bioreactors intercept nitrate-enriched water at the field edge, use a carbon (C) source (typically woodchips) to serve as an electron donor, and create the anaerobic conditions needed to stimulate rapid denitrification, the conversion of nitrate to nitrogen gases (Schipper et al., 2010b). Denitrifying bioreactors were first used to treat nitrate-enriched groundwater (Robertson and Cherry, 1995; Schipper and Vojvodić-Vuković, 1998) and were adapted for use with agricultural tile drainage water (Robertson et al., 2000) and as a polishing step for onsite wastewater treatment (Oakley et al., 2010; Schipper et al., 2010a). These bioreactors are now being used in a variety of agricultural settings for nitrate mitigation from subtropical climates to areas with snow cover. Practitioners and organizations across many sectors in the United States (e.g., watershed groups, nonprofits, extension programs, and governmental agencies such as USDANRCS) are accelerating the adoption of denitrifying bioreactors (Christianson et al., 2012a). Iowa and Illinois nutrient loss reduction strategies include bioreactors as a central technique for reaching nitrate goals (Iowa Nutrient Reduction Strategy, 2013; Illinois Nutrient Loss Reduction Strategy, 2015).

Two basic designs of denitrifying bioreactors (denitrifying walls and denitrifying beds) (Schipper et al., 2010b) as well as laboratory column and small tank studies designed to approximate the flow dynamics of denitrifying beds (e.g., see the early studies of Greenan et al. [2006] and Healy et al. [2006]) were examined. Denitrifying walls (Fig. 1a) are trenches penetrating 1 to $2 \mathrm{~m}$ into the groundwater, dug perpendicular to groundwater flowpaths between the edge-of-field and stream, and filled with wood-based materials that are sometimes mixed with native soil. This process creates a subsurface wall that the groundwater passes

K. Addy, A.J. Gold, and N.A. Ratigan, Dep. of Natural Resources Science, Univ. of Rhode Island, One Greenhouse Rd., Kingston, RI 02881; L.E. Christianson, Dep. of Crop Sciences, Univ. of Illinois, 1102 S. Goodwin, Urbana, Illinois 60801; M.B. David, Dep. of Natural Resources and Environmental Sciences, Univ. of Illinois, $1102 \mathrm{~S}$. Goodwin, Urbana, Illinois 61801; and L.A. Schipper, School of Science, Univ. of Waikato, Private Bag 3105, Hamilton, New Zealand 3240. Assigned to Associate Editor Mark Reiter

Abbreviations: $\mathrm{Cl}$, confidence interval; $\mathrm{HRT}$, hydraulic retention time. 
a
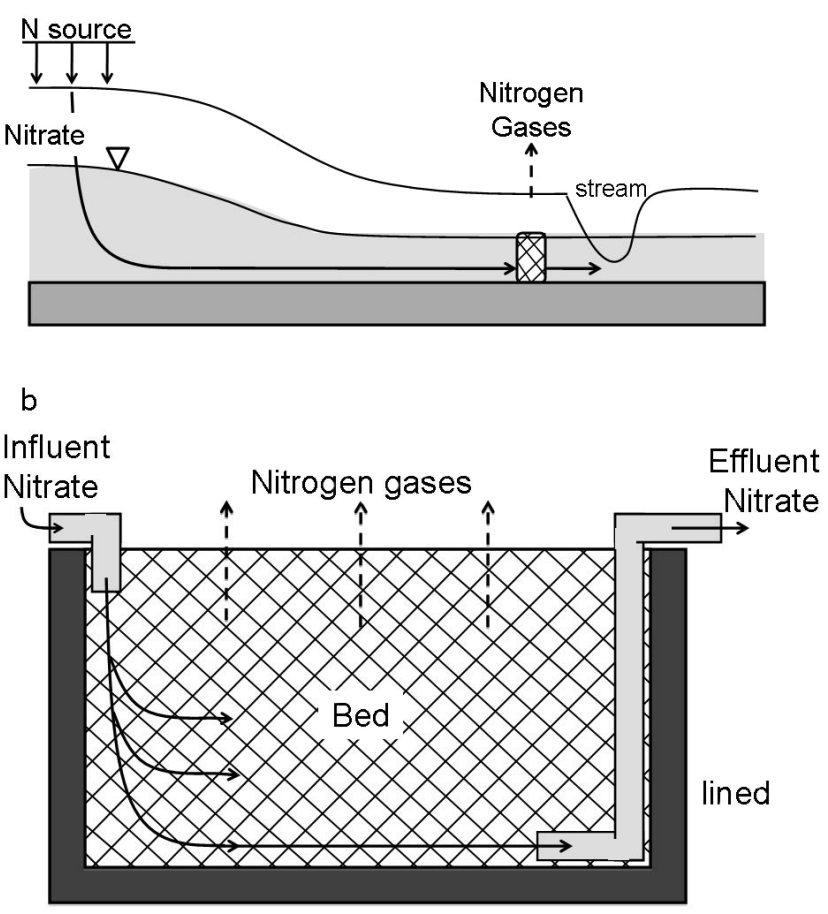

Fig. 1. Schematic of denitrifying bioreactors. (a) Side view of wall installed to impervious layer forcing shallow groundwater through the wall. (b) Side view of a bed treating concentrated discharges of effluent or drainage water. Adapted from Schipper et al. (2010b).

through before discharge into a receiving water body. Inflow to denitrification walls is largely regulated by Darcian flow principles; thus, the nitrate flux per volume of bioreactor media is usually much smaller compared with bed designs (Schipper et al., 2010b). In contrast, denitrifying beds (Fig. 1b) are installed to intercept concentrated flows (e.g., from tile drainage, ditches, or wastewaters) and have also been installed within stream beds (Robertson and Merkley, 2009). Nitrate-laden water is diverted through a trench or container (generally lined) filled with woodbased material and discharged out the other end.

Although previous literature reviews (Schipper et al., 2010b; Christianson et al., 2012a) summarized rates of nitrate removal and potential controls of rates, a quantitative assessment of the literature dealing with denitrifying bioreactor performance has not been performed. The steady publication of denitrifying bioreactor studies during the past two decades (Fig. 2) indicates the timing is right for such an assessment. Here, we applied metaanalysis approaches to investigate nitrate removal rates of denitrifying bioreactors across a range of environmental and design conditions using 26 published studies, in some cases obtaining further information directly from the authors. Meta-analysis combines results across multiple studies and incorporates key aspects of each study within the analyses, such as number of measurements (Burns and Burns, 2008). We asked the following questions: (i) How do different bioreactor designs (i.e., wall, laboratory column, and bed) affect observed nitrate removal rates? (ii) Do wood source, temperature, influent nitrate concentration, age, nitrogen $(\mathrm{N})$ limitation, or hydraulic retention time (HRT) alter nitrate removal rates in denitrifying bioreactors? This quantitative assessment of nitrate removal in denitrifying bioreactors can help to clarify their value, identify constraints,

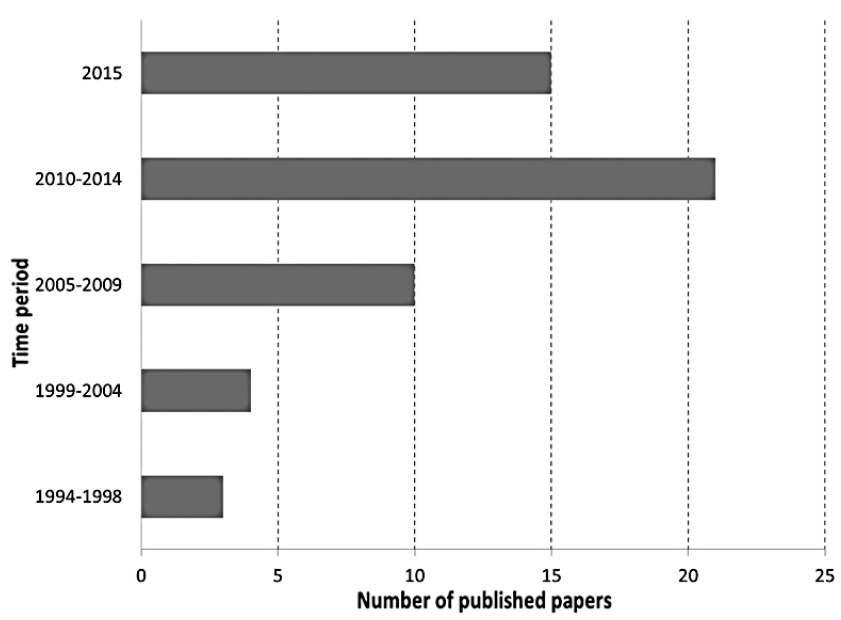

Fig. 2. Number of published papers studying wood-based, flowthrough denitrifying bioreactors from 1994 to 2015 . Note top bar is for a single year rather than a 5-yr interval, through this special issue.

and formulate the future direction and role of these nitrate mitigation strategies.

However, this analysis only focuses on controls of nitrate removal within the bioreactor rather than at the field or watershed scale. Bioreactor nitrate removal effectiveness, particularly in drainage water, is also determined by how much of the tile or other flow passes through the bioreactor. Bed designs can have substantial bypass flow during high flow periods, reducing their effectiveness (Christianson et al., 2013a). Our analysis did not evaluate this aspect of bioreactor design and effectiveness; nor did it evaluate the impacts of bioreactor placement or landscape-driven impacts of performance. Also note that, although we focused on nitrate removal from bioreactors, studies are also emerging that look at possible unintended "pollution swapping," which is the production of soluble or gaseous contaminants, such greenhouse gases, organic $\mathrm{C}$, or metals, by the bioreactor (Fenton et al., 2014; Healy et al., 2012; Warneke et al., 2011c; Schipper et al., 2010b). As additional studies emerge, future holistic assessment of these systems at all scales is warranted.

\section{Materials and Methods}

\section{Data Compilation}

Data were compiled from published peer-reviewed journal articles documenting nitrate removal rates from flow-through, wood-based denitrifying walls, denitrifying beds, and laboratory-scale column studies. We searched the literature using Google Scholar with search terms of denitrification bioreactor, denitrification wall, and denitrification bed. Google Scholar was also useful in forward citation tracking to find additional studies. In addition, we referred to the references of recent papers using "footnote chasing" (White, 2009) and queried researchers in the field for referrals. We focused on studies treating agricultural drainage water with woodchips composed of softwood (i.e., gymnosperms, specifically conifers) or hardwood (i.e., dicot angiosperms). To be included in this study, we required nitrate removal rates in units of mass of nitrate removal per volume of bioreactor per time $\left(\mathrm{g} \mathrm{N} \mathrm{m}^{-3} \mathrm{~d}^{-1}\right)$. If papers reported removal as \% removal or as areal mass removal (e.g., $\mathrm{g} \mathrm{N} \mathrm{m}^{-2} \mathrm{~h}^{-1}$ ), we searched the paper for the required information to transform the 
rates to our required units. In some cases, we queried authors for additional assistance.

Meta-analyses require two pieces of information: (i) the result, such as a mean, and (ii) some measure of variability around the result; for this meta-analysis we used the mean and SD. Throughout this paper, one bioreactor is defined as one unit. In compiling information, we entered the following data into a spreadsheet for each wall, bed, or laboratory column bioreactor unit: author(s), year of publication, article title, journal title, mean nitrate- $\mathrm{N}$ removal rate, the number of measurements taken, and the SD. If these values were not reported, we contacted authors for additional details or original datasets. We were able to gather data on multiple independent bioreactor units from some published studies.

Based on available data from published studies, we created separate spreadsheets for nitrate removal rates associated with the following parameters per bioreactor unit: wood source (hardwood vs. softwood), water temperature, influent nitrate-N concentration, age of unit, presence or absence of $\mathrm{N}$ limitation, and HRT. To augment the datasets, we used Data Thief to obtain additional information from plotted data within the published studies or consulted with authors.

Within each parameter, we created two or three category delineations (e.g., two categories for the qualitative parameters or three range-based categories for quantitative parameters; Table 1). In quantitative assessments, we were often able to use data from a single unit in more than one category. We defined a bed as $\mathrm{N}$ limited if the authors defined their own data as such (often due to $100 \%$ removal in inflow $\mathrm{N}$ ) or if the nitrate- $\mathrm{N}$ concentration in the bed effluent was reported to be $<0.5 \mathrm{mg} \mathrm{N}$ $\mathrm{L}^{-1}$ per the definition of van Driel et al. (2006). Where we had access to more complete datasets, we were often able to obtain both $\mathrm{N}$-limited and non-N-limited data from a single bioreactor unit. For the quantitative parameters, our goal was to have at least six distinct, replicate bioreactor units per category. We also based our analyses on prior bioreactor work related to microbial processing and other hypothesized controlling factors identified in the literature review by Schipper et al. (2010b). For instance, nitrate removal is expected to decline at lower temperatures; $6^{\circ} \mathrm{C}$ (the upper limit of the low temperature category) should reflect groundwater temperatures in winter and early spring of areas that experience colder winters, whereas $17^{\circ} \mathrm{C}$ should reflect summer conditions or more subtropical climates. For the HRT assessment, we normalized the nitrate removal rate for time to give cumulative nitrate removal $\left(\mathrm{g} \mathrm{N} \mathrm{m}^{-3}\right)$.
We found a total of 26 published peer-reviewed journal articles that evaluated nitrate removal rate from flow-through, wood-based denitrifying wall, denitrifying bed, and laboratory column designs that we included in our analyses. These 26 papers included 27 bed units, three wall units, and 27 laboratory column units. Table 2 lists these papers; for each paper, the design type, the number of bioreactor units per design, and the number of bioreactor units in the categorical assessments are also listed. The actual data on mean nitrate removal rates, SD, and number of measurements can be found in Supplemental Tables S1 through S7.

\section{Meta-Analysis}

A meta-analysis was conducted to analyze the response of nitrate removal rate to study type (wall, bed, laboratory column) and the parameters listed in Table 1 using MetaWin version 2.1 (Rosenberg et al., 2000). Effect sizes, which provide a normalized index of the extent of difference between treatment and controls, were calculated for each bioreactor unit. The meta-analysis generated information on significant differences between categories and provided an indication of the comparable magnitude of those differences. Our meta-analysis method weighted the effect size calculations based on the number of measurements and the inverse of the variance for each bioreactor unit (Rosenberg et al., 2000). Because the data are measured on a physical scale, we used the log response ratio to estimate effect size. We used a random effects model, which accounts for the variation in methods between studies and sampling error within individual studies (Rosenberg et al., 2000).

We calculated the response ratio $(\ln R)$, an effect size index, for each bioreactor unit (i.e., the experimental unit) by comparing the experimental mean $\left(\bar{X}^{\mathrm{E}}\right)$ with a control mean $\left(\bar{X}^{\mathrm{C}}\right)$ :

$\ln R=\ln \left(\frac{\bar{X}^{\mathrm{E}}}{\bar{X}^{\mathrm{C}}}\right)$

A response variance of each effect size index was generated from the means, variance $(s)$, and number of measures $(N)$ of the experimental unit and a control unit:

$v_{\ln R}=\frac{\left(s^{\mathrm{E}}\right)^{2}}{N^{\mathrm{E}}\left(X^{\mathrm{E}}\right)^{2}}+\frac{\left(s^{\mathrm{C}}\right)^{2}}{N^{\mathrm{C}}\left(X^{\mathrm{C}}\right)^{2}}$

The studies used in our meta-analysis did not include control treatments (nitrate removal rates without a bioreactor). Strategies in clinical study meta-analyses have emerged to deal with studies without controls among studies with controls, like

Table 1. Ranges of data within categories for the parameters assessed by meta-analysis. Only bed units had sufficient data to permit these analyses.

\begin{tabular}{|c|c|c|c|c|c|}
\hline \multirow{2}{*}{ Parameter } & \multicolumn{5}{|c|}{ Category } \\
\hline & First & Second & Low & Intermediate & High \\
\hline \multicolumn{6}{|l|}{ Qualitative } \\
\hline Wood source & softwood & hardwood & & & \\
\hline N limitation & $\mathrm{N}$ limited & non-N limited & & & \\
\hline \multicolumn{6}{|l|}{ Quantitative } \\
\hline Influent $\mathrm{N}$, mg N L ${ }^{-1}$ & & & $<10$ & $10-30$ & $>30$ \\
\hline $\mathrm{HRT},+\mathrm{d}$ & & & $<6$ & $6-20$ & $>20$ \\
\hline Age of unit, mo & & & $<13$ & $13-24$ & $>24$ \\
\hline Temperature, ${ }^{\circ} \mathrm{C}$ & & & $<6$ & $6-16.9$ & $>16.9$ \\
\hline
\end{tabular}

† Hydraulic retention time. 
a procedure to adjust studies without a control group based on other studies with a control group (Hunter et al., 2014). Similarly, we applied a low control removal rate (mean, $0.1 \mathrm{~g} \mathrm{~N}$ $\left.\mathrm{m}^{-3} \mathrm{~d}^{-1} ; \mathrm{SD}, 0.01\right)$ to all bioreactor studies because we assumed controls would have minimal rates. This rate is equivalent to a change in concentration of $0.07 \mathrm{mg} \mathrm{N} \mathrm{L}^{-1}$ within a bed (assuming a $0.5 \mathrm{~d}$ HRT and porosity of 0.7 ), which we found to be conservative because papers commonly reported the limit of nitrate- $\mathrm{N}$ concentrations only down to the $0.1 \mathrm{mg} \mathrm{N} \mathrm{L}^{-1}$ level. The experimental nitrate removal rates within bioreactor units were generally 15 to 60 times higher than the value used for controls. By using the same control value in each case, we were standardizing the control.

Then, we estimated a weighted cumulative effect size for each category within a given parameter (Rosenberg et al., 2000). The weight for a unit was the reciprocal of its response variance $(w=$ $1 / v)$. Variance-weighted mean effect size was calculated as:

$\overline{\bar{E}}=\frac{\sum_{i=1}^{n} w_{i} \ln R_{i}}{\sum_{i=1}^{n} w_{i}}$

After determining the effect sizes per category, we tested for heterogeneity between categories within each parameter. Significant heterogeneity, like a significant difference but also indicating the strength of the difference, suggests that the individual studies come from different statistical populations $(p<0.1)$ (Rosenberg et al., 2000). If there were more than two categories and heterogeneity between categories was observed ( $p<0.1$ ) (Rosenberg et al., 2000), heterogeneity was tested again in a series of one-by-one comparisons as post hoc testing. Categories with higher effect sizes had higher nitrate removal rates. A bootstrapping (sampling with replacement) procedure with 999 iterations, corrected for bias, was then conducted, which generated $95 \%$ bias-corrected confidence intervals (CIs) on the cumulative effect sizes. We used $p<0.1$ to indicate significant trends.

We used GraphPad Prism version 6.05 to generate forest plots of our meta-analysis results (Fig. 3-5). To provide insight into removal rates for practitioners and decision-makers, we report both the effect size data (as the forest plots is Fig. 3-5) and the back-transformations (Tonitto et al., 2006; Borenstein et al., 2009) to nitrate removal rates (expressed as $\mathrm{g} \mathrm{N} \mathrm{m}^{-3} \mathrm{~d}^{-1}$; see the inset tables in Fig. 3-5) with the 95\% CI also transformed.

With several parameters (temperature, influent $\mathrm{N}$ concentration, and HRT), we also used a continuous meta-analysis procedure to examine if a significant portion of the variation in effect sizes across studies was explained by a linear model using a least squares regression (Rosenberg et al., 2000). It was not possible to conduct a continuous meta-analysis on age because we often did not have the exact age of the unit at each measurement.

Table 2. Published journal articles and overview of data used in meta-analysis of woodchip bioreactor nitrate $\mathrm{N}$ removal rates. The numbers indicate the number of units in the various categorical assessments.

\begin{tabular}{|c|c|c|c|c|c|c|c|c|}
\hline Reference & $\begin{array}{c}\text { Design } \\
\text { type }\end{array}$ & Design & $\begin{array}{l}\text { Wood } \\
\text { source }\end{array}$ & Temperature & $\begin{array}{c}\text { Influent N } \\
\text { concentration }\end{array}$ & Age & $\begin{array}{c}\mathrm{N} \\
\text { limitation }\end{array}$ & HRT† \\
\hline Cameron and Schipper, 2010 & lab & 8 & & 8 & 8 & 8 & 8 & 3 \\
\hline Christianson et al., 2011a & bed & 3 & 3 & 3 & 3 & & 1 & 3 \\
\hline Christianson et al., $2011 \mathrm{~b}$ & bed & 2 & 2 & 2 & 6 & 2 & 2 & 2 \\
\hline Christianson et al., 2012b & bed & 4 & & 8 & 8 & 10 & 8 & 10 \\
\hline Christianson et al., 2013b & bed & 1 & 1 & 1 & 1 & 1 & 2 & 2 \\
\hline Chun et al., 2009 & lab & 1 & & 1 & 1 & 1 & 1 & 1 \\
\hline David et al., 2016 & bed & 1 & 1 & 3 & 2 & 3 & 2 & 3 \\
\hline Elgood et al., 2010 & bed & 1 & & 2 & 1 & 1 & 2 & 2 \\
\hline Gibert et al., 2008 & lab & 1 & & 1 & 1 & 1 & 1 & 1 \\
\hline Greenan et al., 2006 & lab & 1 & & 1 & 1 & 1 & 1 & 1 \\
\hline Healy et al., 2006 & lab & 6 & & 6 & 6 & 6 & 6 & \\
\hline Healy et al., 2012 & lab & 1 & & 1 & 1 & & & \\
\hline Healy et al., 2015 & lab & 1 & & 1 & 1 & 1 & 1 & \\
\hline Lepine et al., 2016 & bed & 4 & & 8 & 8 & 4 & 8 & 7 \\
\hline Moorman et al., 2010 & wall & 1 & & & & & & \\
\hline Pluer et al., 2016 & bed & 3 & 3 & & 6 & 3 & 3 & \\
\hline Pluer et al., 2016 & lab & 1 & & & & & & \\
\hline Robertson, 2010 & lab & 4 & & 4 & 3 & 4 & 4 & 4 \\
\hline Robertson and Merkley, 2009 & bed & 1 & & 3 & 1 & 2 & 2 & \\
\hline Robertson et al., 2009 & bed & 1 & & 2 & & 4 & 1 & \\
\hline Schipper and Vojvodić-Vuković, 2000 & wall & 1 & & & & & & \\
\hline Schipper et al., 2010a & bed & 3 & 3 & & 5 & 5 & 4 & 3 \\
\hline Schmidt and Clark, 2012 & wall & 1 & & & & & & \\
\hline Warneke et al., 2011a & bed & 1 & 1 & 1 & 1 & & 1 & 1 \\
\hline Warneke et al., 2011b & bed & 1 & 1 & 2 & 1 & 2 & 1 & 1 \\
\hline Warneke et al., 2011c & lab & 3 & & 6 & 3 & & 3 & 6 \\
\hline Woli et al., 2010 & bed & 1 & 1 & & 2 & 2 & 2 & 1 \\
\hline
\end{tabular}

† Hydraulic retention time. 


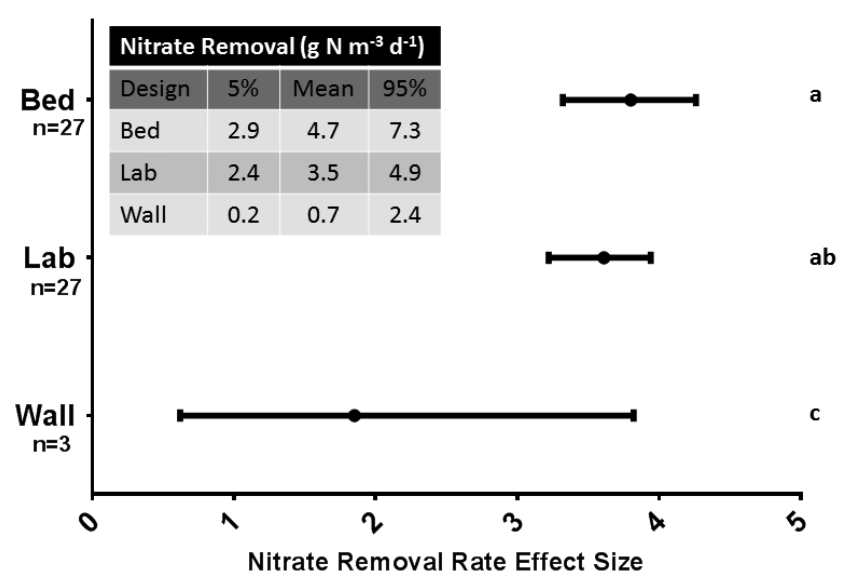

Fig. 3. Mean nitrate removal rate effect size and $95 \%$ bias-corrected confidence interval by bioreactor design (bed, laboratory column, and wall). Bars with different letters were significantly different $(p<$ $0.05) ; n$ values represent number of units of that type of bioreactor used in the analysis. Inset table indicates the back-calculated mean nitrate removal rate $\left(\mathrm{g} \mathrm{N} \mathrm{m}^{-3} \mathrm{~d}^{-1}\right)$ with $95 \%$ bias-corrected confidence interval by bioreactor design (trends remain the same).

\section{Results and Discussion}

Our meta-analysis is the first quantitative synthesis of the published literature describing the response of nitrate removal rates in bioreactors to design, wood source, temperature, influent nitrate concentration, $\mathrm{N}$ limitation, age of unit, and HRT. More than 2500 observations from 26 papers were included. Bed and laboratory column designs constituted approximately 61 and $37 \%$ of the observations, respectively. The focus of this meta-analysis was on nitrate removal only, but future assessments of bioreactors should also include a holistic analysis of multiple contaminants to determine risks related to pollution swapping from these C-rich, anaerobic units.

\section{Response to Design Category}

Nitrate removal rates in bed and laboratory column designs were not significantly different from each other, but both were higher than walls $(p<0.05$; note the low number of units for wall studies $[n=3]$ ) (Fig. 3). In a qualitative review of bioreactors, Schipper et al. (2010b) also noted that walls generally had lower nitrate removal rates $\left(0.01-3.6 \mathrm{~g} \mathrm{~N} \mathrm{~m}^{-3} \mathrm{~d}^{-1}\right)$ than beds $(2-22 \mathrm{~g}$ $\mathrm{N} \mathrm{m}^{-3} \mathrm{~d}^{-1}$ ). Walls are frequently used in $\mathrm{N}$-limiting conditions, which may explain the lower nitrate removal rate; influent $\mathrm{N}$ concentrations are often lower and HRT is often longer in walls than in bed designs.

We were unable to complete categorical assessments on wall studies as there were only three units. Even though bed and laboratory column nitrate removal were not significantly different, we chose to determine categorical trends within each design separately because field conditions are often more variable than laboratory-controlled conditions. Laboratory study results are often used to provide process-level insight. When we assessed the responses of temperature, influent $\mathrm{N}$ concentration, $\mathrm{N}$ limitation, and age to nitrate removal rates in laboratory column designs, we found no significant differences between categories within each parameter. For most of these parameters, laboratory column studies frequently encompassed a smaller range of conditions than field studies; only 4 of the 10 lab studies had more than one column unit for categorical parameter assessments (Table 2), limiting our capacity to conduct rigorous analyses. In contrast, 14 of the 15 bed studies reported data on multiple bed units within different categories of several parameters (Table 2). All further meta-analyses results presented are from the bed designs.

\section{Bed Wood Source}

There was no significant difference in nitrate removal rates between different wood sources (Fig. 4a). Nitrate removal was apparently not limited by the $\mathrm{C}$ supply of either wood source even though the lignin in softwoods is expected to be more recalcitrant per mass than in hardwoods (Cornwell et al., 2009). Cameron and Schipper (2010) also found no significant differences based on wood source in laboratory columns. Wood density indirectly effects decomposition. Low-density woods like softwoods, often Pinus species in these bed studies, allow oxygen into dead wood, which make them more subject to decay and depletion of C supply more quickly than denser woods (Cornwell et al., 2009); this may limit nitrate removal over time. However, the beds within our assessment encompassed a range of ages. Hardwood density varies widely between species (Cornwell et al., 2009), and hardwood bed studies rarely specified the species or just indicated a mix of hardwoods. In locations where hardwood is more expensive and not as accessible (Schipper et al., 2010b), the use of softwood may be preferred without limiting nitrate removal. The 95\% CIs encompassed a large range of rates, and there may be undetected differences between wood types.

Other carbonaceous materials, such as maize cobs, have been used in laboratory column designs (Cameron and Schipper, 2010), but extended in-field assessment of the nitrate removal with these materials over time is warranted to establish if lability and removal rates decline rapidly over time.

\section{Bed Influent N Concentration}

Influent $\mathrm{N}$ concentration significantly influenced nitrate removal rate (Fig. 4b). Beds with influent $\mathrm{N}$ concentrations $>30$ mg N L ${ }^{-1}$ had higher nitrate removal rates than beds with intermediate $\left(10-30 \mathrm{mg} \mathrm{N} \mathrm{L}{ }^{-1} ; p<0.1\right)$ or low ( $<10 \mathrm{mg} \mathrm{N} \mathrm{L}^{-1} ; p$ $<0.05)$ concentrations. There were also significant differences between beds with intermediate and low influent $\mathrm{N}$ concentrations $(p<0.1)$. Whereas nitrate removal in bioreactors has been often considered to be zero-order kinetics where the reaction rate is controlled by a parameter other than concentration (Schipper et al., 2010b), we have observed lower removal at lower concentrations, which emphasizes the importance of taking $\mathrm{N}$ limitation into consideration for bioreactor design. The use of higher design removal rates may be warranted for situations with high nitrate- $\mathrm{N}$ concentrations, such as settings with high $\mathrm{N}$ inputs on irrigated lands in Mediterranean or arid climates (Los Huertos et al., 2001).

\section{Bed Hydraulic Retention Time}

Cumulative nitrate removal in beds with HRT $<6$ h was significantly lower than in beds with HRT from 6 to $20 \mathrm{~h}$ and $>20$ h $(p<0.05)$ (Fig. 4c). Designers of beds should seek to optimize the system for expected flow rates to ensure sufficient time 


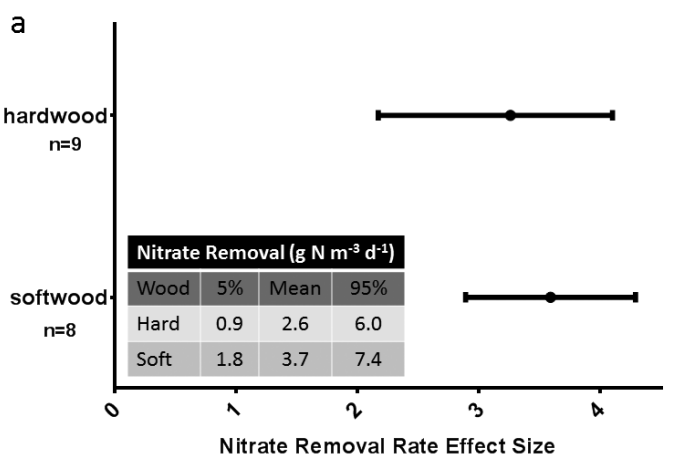

c

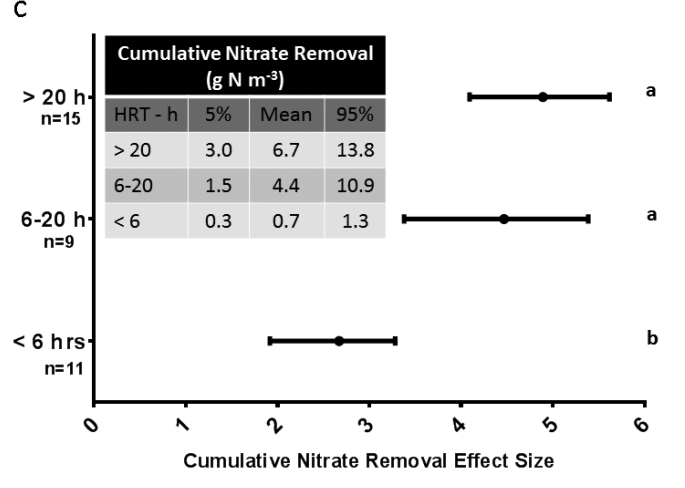

b
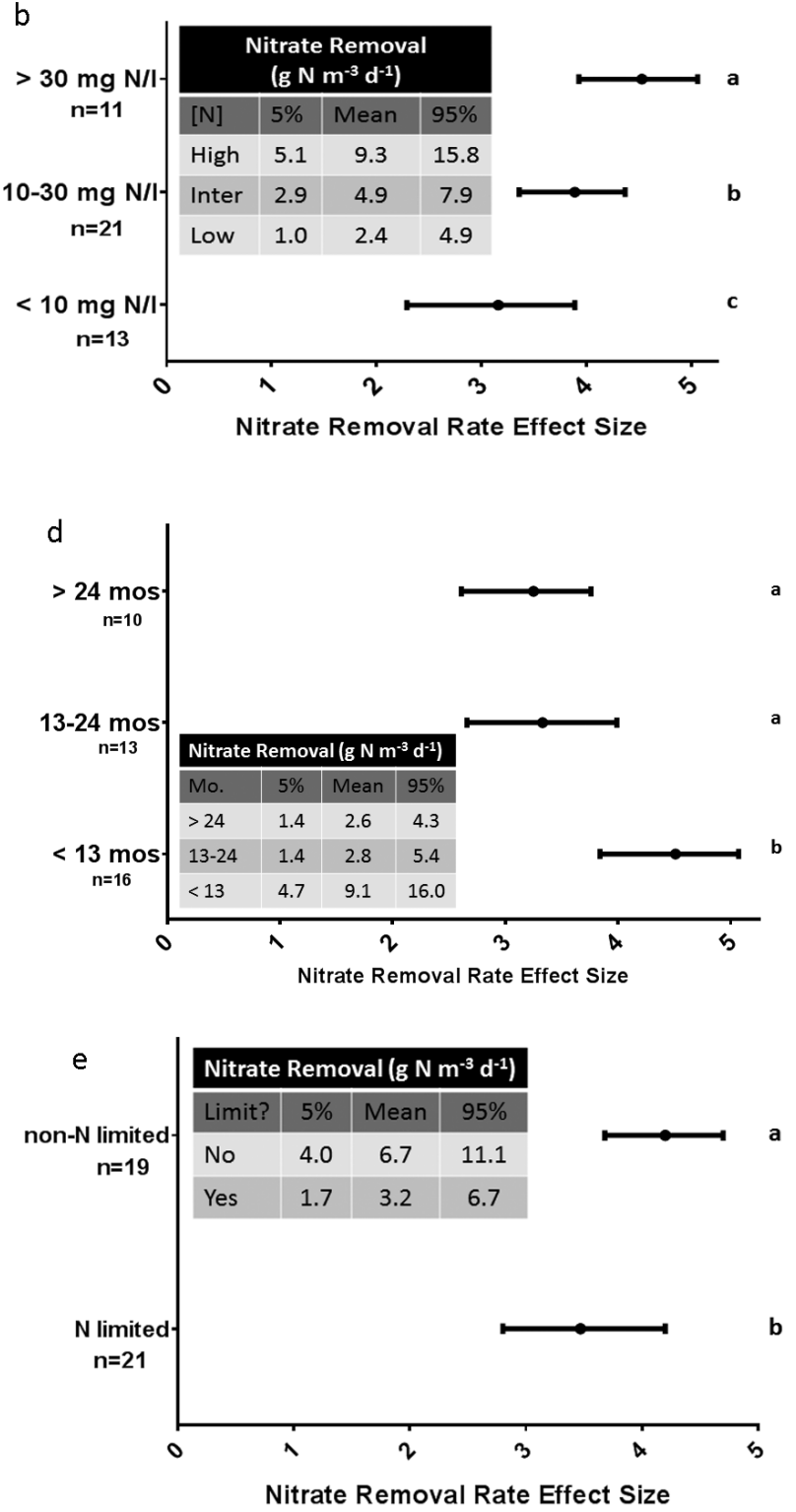

Fig. 4. Mean nitrate removal rate effect size of beds and $95 \%$ bias-corrected confidence interval by different categories of (a) wood source, (b) influent $\mathrm{N}$ concentration, (c) hydraulic retention time (HRT), (d) age of unit, and (e) N limitation. Bars with different letters were significantly different ( $p$ $<0.05$ or $p<0.1$ ); $n$ values represent number of bed units in that category that were used in the analysis. Inset tables indicate the back-calculated mean nitrate removal rate ( $\mathrm{g} \mathrm{N} \mathrm{m}^{-3} \mathrm{~d}^{-1}$ for Fig. $\mathrm{a}, \mathrm{b}$ and $\mathrm{d} ; \mathrm{g} \mathrm{N} \mathrm{m}^{-3}$ for Fig. c) with $95 \%$ bias-corrected confidence interval by category (trends remain the same).

for nitrate removal (Christianson et al., 2012a). Many denitrifying bed designs now incorporate hydraulic control components that can adjust the extent of bypass flow during high flow events. These design features can provide extended HRT if desired and also permit the flexibility to further examine nitrate removal under different HRT strategies (Christianson et al., 2012a).

\section{Bed Age}

Bed age was found to affect the response of nitrate removal significantly (Fig. 4d). Beds less than 13 mo old had significantly higher nitrate removal rates than those 13 to 24 mo old and $>25$ mo old $(p<0.05)$. The $95 \% \mathrm{CI}$ and mean removal rate effect size of the two older age categories were similar and did not display significant differences. Our results concur with the suggestion of Schipper et al. (2010b) and Robertson
(2010) that rates after the first year represent the long-term operational rates; thus, removal rates obtained in the first year of a new bioreactor should be viewed with caution. In addition to changes in removal rates within the first year, there can be concerns with flushing of dissolved organic $\mathrm{C}$ from bioreactors (Schipper et al., 2010b; Healy et al., 2012; Fenton et al., 2014). These conditions are well documented at start-up, but further information, such as the cumulative number of water pore volumes that encompass a flushing period and whether extended periods of dryness can induce another flushing period, would improve interpretation of monitoring results. Note that only two of the beds in the high category were more than 36 mo old (Christianson et al., 2012b; Robertson et al., 2009). Bioreactors are commonly viewed as a decadal management practices, so there is a striking need to monitor older beds as 
they age to determine if and how the operational rates change over extended times.

\section{Bed N Limitation}

We also examined if nitrate- $\mathrm{N}$ limitation (bed effluent $<0.5$ $\mathrm{mg} \mathrm{N} \mathrm{L}{ }^{-1}$ ) affected the observed rates of bed nitrate removal (Fig. 4e). We found non-N-limited beds to have higher nitrate removal rates $(p<0.1)$ than those that were $\mathrm{N}$ limited, as expected. Bed designers should consider periods of potential $\mathrm{N}$ limitation as potential environmental risks because the absence of nitrate as an electron acceptor in an anaerobic setting can produce conditions that generate unfavorable by-products, such as methane, methyl mercury, or hydrogen sulfide (Schipper et al., 2010b; Fenton et al., 2014).

\section{Bed Temperature}

Biological rates are well known to increase with increasing temperatures. We found this general trend in our categorical
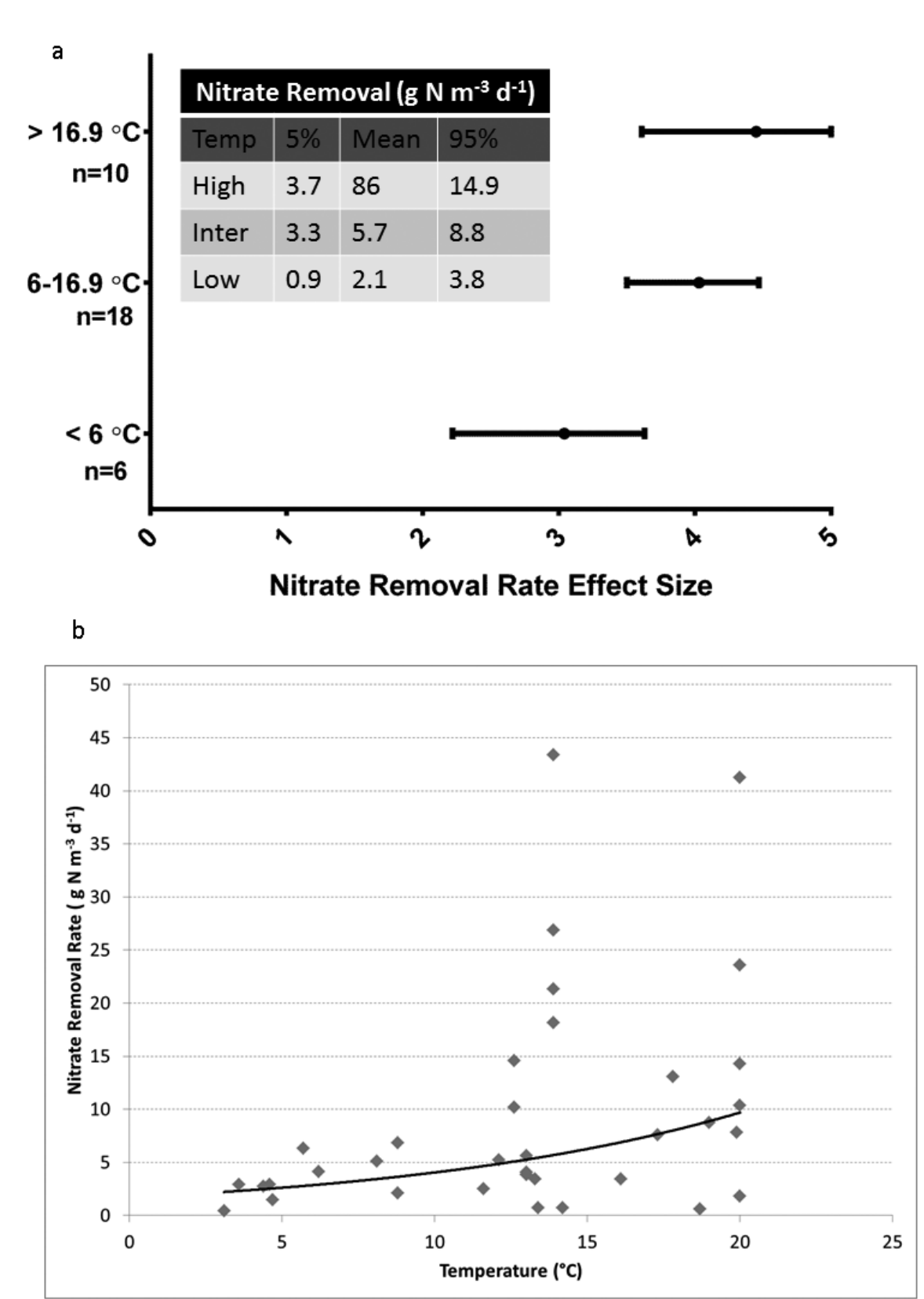

assessment of temperature in denitrifying beds. Beds with temperatures below $6^{\circ} \mathrm{C}$ had lower nitrate removal than those at intermediate temperatures of 6 to $16.9^{\circ} \mathrm{C}(p<0.1$; i.e., the approximate range of midwestern US groundwater temperature) and temperatures higher than $16.9^{\circ} \mathrm{C}(p<0.05)$ (Fig. $5 a)$. Although the high temperature category had a substantial number of bed nitrate removal rates that were higher than those observed within the intermediate category, there was no significant difference likely due to the variability. A linear model found that temperature explained a substantial portion of the variation in effect sizes $(\ln R)$ across bed studies $(p<0.1$; $\mathrm{N}$ removal rate $=1.79 e^{0.0766 \times \text { Temperature }}$ after back-transformation from variance-weighted mean effect sizes) (Fig. 5b). This regression yielded a $Q_{10}$ of 2.15 (i.e., the factor by which the removal rate increases for each $10^{\circ} \mathrm{C}$ increase), very similar to that reported across bioreactor literature (Cameron and Schipper, 2010; Warneke et al., 2011b). Influent nitrate concentration
Fig. 5. Mean nitrate removal rate effect size of beds and $95 \%$ bias-corrected confidence interval by different categories of temperature (a). Bars with different letters were significantly different $(p<0.1) ; n$ values represent number of bed units in that category that were used in the analysis. Inset tables indicate the backcalculated mean nitrate removal rate $(\mathrm{g} \mathrm{N}$ $\mathrm{m}^{-3} \mathrm{~d}^{-1}$ ) with $95 \%$ bias-corrected confidence interval by category (trends remain the same). A significant linear model relationship (b) $(p<$ 0.1 ) was found between variance-weighted mean effect sizes versus temperature, here back-transformed to nitrate removal rates versus temperature. 
and HRT did not generate a significant result from continuous linear meta-analysis procedures.

Our results strengthen the observation of Schipper et al. (2010b) that bioreactors can generate nitrate removal rates at low temperatures. For example, at the mean nitrate removal rate of $2 \mathrm{~g} \mathrm{~N} \mathrm{~m}^{-3} \mathrm{~d}^{-1}$ at $<6^{\circ} \mathrm{C}$, a bed with a hydraulic retention of $12 \mathrm{~h}$ could lower nitrate- $\mathrm{N}$ concentrations by $1 \mathrm{~g} \mathrm{~N} \mathrm{~m}^{-3}$. The importance of these rates for curtailing nitrate flux will be site dependent and require estimates of the distribution of input nitrate- $\mathrm{N}$ concentrations and water flux to the bioreactor during cold conditions. Additional studies using temperature-controlled laboratory methods would be useful to further explore nitrate removal at low temperatures because previous laboratory designs have only gone down to $10^{\circ} \mathrm{C}$ (Greenan et al., 2006; Healy et al., 2006). In designing beds for use in cold conditions, it is important to consider that low temperatures often coincide with periods of low evapotranspiration and/or periods of snowmelt, potentially resulting in high water and $\mathrm{N}$ flux. To generate higher nitrate removal in these cooler, high-flow situations, the volume of the bioreactor and extent of inflow should be designed to allow adequate HRT; however, this must be balanced with the consideration of very low flow conditions later in the season to avoid nearly stagnant conditions within the bioreactor. The concept of permeable reactive interceptors, a modified denitrifying bioreactor with additional remediation cells for other specific contaminants or the capacity to deal with high temporal variation in contaminant fluxes (Fenton et al., 2014), deserves further research.

\section{Conclusions}

Denitrifying bioreactors as nitrate mitigation strategies hold promise for reducing water quality degradation in agricultural watersheds and in polishing treatment of some wastewaters. Lessons from this meta-analysis can be incorporated into bed designs, especially extending HRT to manage nitrate removal under low temperature conditions and during high flows. Laboratory column studies are warranted for comparative assessment of nitrate removal under low temperatures, high flows, and conditions approaching $\mathrm{N}$ limitation. Field-based bed studies are needed to determine rates in different landscapes, nitrate loading, and climatic setting. Continued monitoring of established beds more than $24 \mathrm{mo}$ after installation will help assess possible $\mathrm{C}$ lability decline over time. To advance our understanding of bioreactor performance and to refine design parameters, future work should report nitrate removal rates in units of mass of $\mathrm{N}$ removal per volume of bioreactor per time $\left(\mathrm{g} \mathrm{N} \mathrm{m}^{-3} \mathrm{~d}^{-1}\right)$, SDs, numbers of measurements, and other environmental parameters, including wood source, influent $\mathrm{N}$ concentration, temperature, age, presence of $\mathrm{N}$ limitation (effluent $\mathrm{N}$ concentration $<0.5 \mathrm{mg}$ $\mathrm{N} \mathrm{L}^{-1}$ ), and HRT. When sufficient data become available, there is a need for similar meta-analyses of other gaseous and solute removal and production rates from denitrifying bioreactors, like greenhouse gas, phosphorus, organic $\mathrm{C}$, and metals.

\section{Acknowledgments}

The authors thank all authors of the published denitrifying bioreactor papers cited in our meta-analysis for answering our questions and often generously donating raw data sets to allow for the refinement of categorical analyses, undergraduate Jill Raval for assisting with initial data harvesting and organization, and the reviewers for insightful comments on drafts of this manuscript. This material was based on work supported by USDA-NIFA Agreement No. 2011-5113031120, USDA-ARS Agreement No. 59-1930-0-046, the Rhode Island Agricultural Experiment Station (no. 5436), and URI Cooperative Extension. Any opinions, findings, conclusions, or recommendations expressed in this publication are those of the authors and do not necessarily reflect the view of the USDA.

\section{References}

Billen, G., J. Garnier, and L. Lassaletta. 2013. The nitrogen cascade from agricultural soils to the sea: Modelling nitrogen transfers at regional watershed and global scales. Philos. Trans. R. Soc. B 368:20130123. doi:10.1098/ rstb.2013.0123

Borenstein, M., L.V. Hedges, J.P.T. Higgins, and H.R. Rothstein. 2009. Introduction to meta-analysis. John Wiley \& Sons, New York.

Burns, R., and R. Burns. 2008. Business research methods and statistics using SPSS. Sage Publishing, Thousand Oaks, CA.

Cameron, S.G., and L.A. Schipper. 2010. Nitrate removal and hydraulic performance of organic carbon for use in denitrification beds. Ecol. Eng. 36:1588-1595. doi:10.1016/j.ecoleng.2010.03.010

Christianson, L.E., A. Bhandari, and M.J. Helmers. 2012a. A practice-oriented review of woodchip bioreactors for subsurface agricultural drainage. Appl. Eng. Agric. 28:861-874. doi:10.13031/2013.42479

Christianson, L.E., A. Bhandari, and M.J. Helmers. 2011a. Pilot-scale evaluation of denitrification drainage bioreactors: Reactor geometry and performance. J. Environ. Eng. 137:213-220. doi:10.1061/(ASCE) EE.1943-7870.0000316

Christianson, L., A. Bhandari, M. Helmers, K. Kult, T. Sutphin, and R. Wolf. 2012b. Performance evaluation of four field-scale agricultural drainage denitrification bioreactors in Iowa. Trans. Am. Soc. Agric. Eng. 55:2163-2174.

Christianson, L., R. Christianson, M. Helmers, C. Pederson, and A. Bhandari. 2013a. Modeling and calibration of drainage denitrification bioreactor design criteria. J. Irrig. Drain. Eng. 139:699-709. doi:10.1061/(ASCE) IR.1943-4774.0000622

Christianson, L.E., J.A. Hanly, and M.J. Hedley. 2011b. Optimized denitrification bioreactor treatment through simulated drainage containment. Agric. Water Manage. 99:85-92. doi:10.1016/j.agwat.2011.07.015

Christianson, L., M. Helmers, A. Bhandari, and T. Moorman. 2013b. Internal hydraulics of an agricultural drainage denitrification bioreactor. Ecol. Eng. 52:298-307. doi:10.1016/j.ecoleng.2012.11.001

Chun, J.A., R.A. Cooke, J.W. Eheart, and M.S. Kang. 2009. Estimation of flow and transport parameters for woodchip-based bioreactors: I. Laboratory-scale bioreactor. Biosystems Eng. 104:384-395. doi:10.1016/j. biosystemseng.2009.06.021

Cornwell, W.K., J.H.C. Cornelissen, S.D. Allison, J. Bauhus, P. Eggleton, C.M. Preston, F. Scarff, J.T. Weedon, C. Wirth, and A.E. Zanne. 2009. Plant traits and wood fates across the globe: Rotted, burned, or consumed? Glob. Change Biol. 15:2431-2449. doi:10.1111/j.1365-2486.2009.01916.x

David, M.B., L.E Gentry, R.A. Cooke, and S.M Herbstritt. 2016. Temperature and substrate control woodchip bioreactor performance in reducing tile nitrate loads in east-central Illinois. J. Environ. Qual. doi:10.2134/ jeq2015.06.0296

Diaz, R.J. 2001. Overview of hypoxia around the world. J. Environ. Qual. 30:275-281. doi:10.2134/jeq2001.302275x

Elgood, Z., W.D. Robertson, S.L. Schiff, and R. Elgood. 2010. Nitrate removal and greenhouse gas production in a stream-bed denitrifying bioreactor. Ecol. Eng. 36:1575-1580. doi:10.1016/j.ecoleng.2010.03.011

Erisman, J.W., J.N. Galloway, S. Seitzinger, A. Bleeker, N.B. Dise, A.M.R. Petrescu, A.M. Leach, and W. de Vries. 2013. Consequences of human modification of the global nitrogen cycle. Phil. Trans. R. Soc. B 368:210130116.

Fenton, O., M.G. Healy, F. Brennan, M.M.R. Jahangir, G.J. Lanigan, K.G. Richards, S.F. Thornton, and T.G. Ibrahim. 2014. Permeable reactive interceptors: Blocking diffuse nutrient and greenhouse gases losses in key area of the farming landscape. J. Agric. Sci. 152:71-81. doi:10.1017/ S0021859613000944

Gibert, O., S. Pomierny, I. Rowe, and R.M. Kalin. 2008. Selection of organic substrates as potential reactive materials for use in a denitrification permeable reactive barrier (PRB). Bioresour. Technol. 99:7587-7596. doi:10.1016/j. biortech.2008.02.012

Greenan, C.M., T.B. Moorman, T.C. Kaspar, T.B. Parkin, and D.B. Jaynes. 2006. Comparing carbon substrates for denitrification of subsurface drainage water. J. Environ. Qual. 35:824-829. doi:10.2134/jeq2005.0247 
Healy, M.G., M. Barrett, G.J. Lanigan, A. Joao Serrenho, T.G. Ibrahim, S.F. Thornton, S.A. Rolfe, W.E. Huang, and O. Fenton. 2015. Optimizing nitrate removal and evaluating pollution swapping trade-offs from a laboratory denitrification bioreactors. Ecol. Eng. 74:290-301. doi:10.1016/j. ecoleng.2014.10.005

Healy, M.G., T.G. Ibrahim, G.J. Lanigan, A. Joao Serrenho, and O. Fenton. 2012. Nitrate removal rate, efficiency and pollution swapping potential of different organic carbon media in laboratory denitrification bioreactors. Ecol. Eng. 40:198-209. doi:10.1016/j.ecoleng.2011.12.010

Healy, M.G., M. Rodgers, and J. Mulqueen. 2006. Denitrification of a nitraterich synthetic wastewater using various wood-based media materials. J. Environ. Sci. Health A Tox. Hazard. Subst. Environ. Eng. 41:779-788. doi:10.1080/10934520600614371

Howarth, R.W. 2008. Coastal nitrogen pollution: A review of sources and trends globally and regionally. Harmful Algae 8:14-20. doi:10.1016/j. hal.2008.08.015

Howarth, R.W., D.M. Anderson, T.M. Church, H. Greening, C.S. Hopkinson, W.C. Huber, N. Marcus, R.J. Naiman, K. Segerson, A. Sharpley, and W.J. Wiseman. 2000. Clean coastal waters: Understanding and reducing the effects of nutrient pollution. National Academy Press, Washington, DC.

Hunter, J.E., J.L. Jensen, and R. Rodgers. 2014. The control group and metaanalysis. J. Methods Meas. Soc. Sci. 5:3-21.

Illinois Nutrient Loss Reduction Strategy. 2015. Illinois Environmental Protection Agency. www.epa.illinois.gov/topics/water-quality/watershed-management/excess-nutrients/index (accessed 20 July 2015).

Iowa Nutrient Reduction Strategy. 2013. A science and technology-based framework to assess and reduce nutrients to Iowa waters and the Gulf of Mexico. Iowa Department of Agriculture and Land Stewardship, Iowa Department of Natural Resources, and Iowa State University College of Agriculture and Life Sciences, Ames, IA.

Lepine, C., L. Christianson, K. Sharrer, and S. Summerfelt. 2016. Optimizing hydraulic retention times in denitrifying woodchip bioreactors treating recirculating aquaculture system wastewater. J. Environ. Qual. doi:10.2134/ jeq2015.05.0242

Los Huertos, M., L.E. Gentry, and C. Shennan. 2001. Land use and stream nitrogen concentrations in agricultural watersheds along the central coast of California. Sci. World J. 1:615-622. doi:10.1100/tsw.2001.315

Moorman, T.B., T.B. Parkin, T.C. Kaspar, and D.B. Jaynes. 2010. Denitrification activity, wood loss, and $\mathrm{N}_{2} \mathrm{O}$ emissions over 9 years from a wood chip bioreactor. Ecol. Eng. 36:1567-1574. doi:10.1016/j.ecoleng.2010.03.012

Nixon, S.W., B. Buckley, S. Granger, and J. Bintz. 2001. Responses of very shallow marine ecosystems to nutrient enrichment. Hum. Ecol. Risk Assess. 7:1457-1481. doi:10.1080/20018091095131

Oakley, S.M., A.J. Gold, and A.J. Oczkowski. 2010. Nitrogen control through decentralized wastewater treatment: Process performance and alternative management strategies. Ecol. Eng. 36:1520-1531. doi:10.1016/j. ecoleng.2010.04.030

Pluer, W.T., L.D. Geohring, T.S. Steenhuis, and M.T. Walter. 2016. Controls influencing the treatment of excess agricultural nitrate with denitrifying bioreactors. J. Environ. Qual. doi:10.2134/jeq2015.06.0271

Robertson, W.D. 2010. Nitrate removal rates in woodchip media of varying age. Ecol. Eng. 36:1581-1587. doi:10.1016/j.ecoleng.2010.01.008

Robertson, W.D., D.W. Blowes, C.J. Ptacek, and J.A. Cherry. 2000. Long-term performance of in situ reactive barriers for nitrate remediation. Ground Water 38:689-695. doi:10.1111/j.1745-6584.2000.tb02704.x
Robertson, W.D., and J.A. Cherry. 1995. In situ denitrification of septic-system nitrate using reactive porous media barriers: Field trials. Ground Water 33:99-111. doi:10.1111/j.1745-6584.1995.tb00266.x

Robertson, W.D., and L.C. Merkley. 2009. In-stream bioreactor for agricultural nitrate treatment. J. Environ. Qual. 38:230-237. doi:10.2134/ jeq2008.0100

Robertson, W.D., C.J. Ptacek, and S.J. Brown. 2009. Rates of nitrate and perchlorate removal in a 5-year-old wood particle reactor treating agricultural drainage. Groundwater Monit. Rem. 29:87-94. doi: $10.1111 /$ j.1745-6592.2009.01231.x

Rosenberg, M.S., D.C. Adams, and J. Burevitch. 2000. Metawin statistical software for meta-analysis, Sinauer Associates, Inc., Sunderland, MA.

Schipper, L.A., S.C. Cameron, and S. Warneke. 2010a. Nitrate removal from three different effluents using large-scale denitrification beds. Ecol. Eng. 36:1552-1557. doi:10.1016/j.ecoleng.2010.02.007

Schipper, L.A., W.D. Robertson, A.J. Gold, D.B. Jaynes, and S.C. Cameron. 2010b. Denitrifying bioreactors: An approach for reducing nitrate loads to receiving waters. Ecol. Eng. 36:1532-1543. doi:10.1016/j. ecoleng.2010.04.008

Schipper, L.A., and M. Vojvodić-Vuković. 1998. Nitrate removal from groundwater using a denitrification wall amended with sawdust: Field trial. J. Environ. Qual. 27:664-668. doi:10.2134/jeq1998.00472425002700030025x

Schipper, L.A., and M. Vojvodić-Vuković. 2000. Nitrate removal from groundwater and denitrification rates in a porous treatment wall amended with sawdust. Ecol. Eng. 14:269-278. doi:10.1016/S0925-8574(99)00002-6

Schmidt, C.A., and M.W. Clark. 2012. Efficacy of a denitrification wall to treat continuously high nitrate loads. Ecol. Eng. 42:203-211. doi:10.1016/j. ecoleng.2012.02.006

Tonitto, C., M.B. David, and L.E. Drinkwater. 2006. Replacing bare fallows with cover crops in fertilizer-intensive cropping systems: A meta-analysis of crop yield and N dynamics. Agric. Ecosyst. Environ. 112:58-72. doi:10.1016/j. agee.2005.07.003

van Driel, P.W., W.D. Robertson, and L.C. Merkley. 2006. Denitrification of agricultural drainage using wood-based reactors. Trans. ASABE 49:565573. doi:10.13031/2013.20391

Warneke, S., L.A. Schipper, D.A. Bruesewitz, I. Mcdonald, and S. Cameron. 2011c. Rates, controls and potential adverse effects of nitrate removal in a denitrification bed. Ecol. Eng. 37:511-522. doi:10.1016/j. ecoleng.2010.12.006

Warneke, S., L.A. Schipper, D.A. Bruesewitz, and W.T. Baisden. 2011a. A comparison of different approaches for measuring denitrification rates in a nitrate removing bioreactor. Water Res. 45:4141-4151. doi:10.1016/j. watres.2011.05.027

Warneke, S., L.A. Schipper, M.G. Matiasek, K.M. Scow, S. Cameron, D.A. Bruesewitz, and I.R. Mcdonald. 2011b. Nitrate removal, communities of denitrifiers and adverse effects in different carbon substrates for use in denitrification beds. Water Res. 45:5463-5475. doi:10.1016/j.watres.2011.08.007

White, H.D. 2009. Scientific communication and literature retrieval. In: H. Cooper, et al., editors, The handbook of research synthesis and meta-analysis. 2nd ed. Russel Sage Foundation, New York. p. 51-71.

Woli, K.P., M.B. David, R.A. Cooke, G.F. Mcisaac, and C.A. Mitchell. 2010. Nitrogen balance in and export from agricultural fields associated with controlled drainage systems and denitrifying bioreactors. Ecol. Eng. 36:15581566. doi:10.1016/j.ecoleng.2010.04.024 